\title{
The Role of Habit, Childhood Consumption, Familiarity and Attitudes across Seafood Consumption Segments in Australia
}

\author{
Dr Dawn Birch \\ University of the Sunshine Coast, Queensland, Australia \\ Dr Meredith Lawley \\ University of the Sunshine Coast, Queensland, Australia
}

Australian consumers hold very favourable attitudes toward seafood with key drivers to consumption being taste, convenience, diet variety and health benefits. Nevertheless, despite these positive attitudes, seafood consumption remains below many other countries. In this paper, we investigate the influence of habit including regular childhood consumption, familiarity with seafood, and attitudes toward seafood on seafood consumption and consumption occasions. Habit and lack of familiarity with seafood were found to lead to lower levels of seafood consumption, while positive attitudes toward seafood were associated with more regular seafood consumption. People who consumed seafood on a regular basis as a child were more likely to be more familiar with seafood and be in the habit of consuming seafood in adulthood. Patterns of childhood consumption occasions were found to be associated with adult consumption occasions. Based on these findings, we discuss possible strategies and behavioural interventions for further investigation, which are grounded in habit theory and are aimed at changing seafood eating habits, increasing childhood consumption, and reducing the lack of familiarity with seafood.

KEYWORDS: seafood, consumption, habit, childhood consumption, fish, familiarity, Australia, behavioural interventions 


\section{INTRODUCTION}

Compared with many European and Asian countries, seafood is not a regular part of the traditional diet of many western countries. Consumption of seafood in Australia has slowly risen to an average of 2.2 weekly serves per capita in 2011; however, many Australians are still consuming less than recommended levels (Danenberg \& Mueller, 2011). Despite Australians holding very positive attitudes toward seafood in terms of its taste, convenience, diet variety and health benefits, these favourable attitudes are not translating into higher levels of seafood consumption (Birch, Lawley, \& Hamblin, 2012). In this paper, we investigate the influence of habit including regular childhood seafood consumption, familiarity with seafood, and attitudes toward seafood on seafood consumption and consumption occasions across consumption segments (regular, light and very light seafood consumers). Based on the findings we discuss potential strategies and behavioural interventions which are aimed at encouraging increased seafood consumption by: (1) changing existing seafood habits; (3) encouraging increased childhood consumption; and (3) addressing lack of familiarity with seafood.

Key drivers of seafood consumption are well documented and include taste, health benefits and diet variety (Bredahl \& Grunert, 1997; Olsen, 2004; Rortveit \& Olsen, 2009). In particular, taste has been found to be an important driver of food choice and people who like the taste of fish are more likely to be regular consumers of seafood (Bruns $\varnothing$, Verbeke, Olsen \& Jeppesen, 2009). The theory of planned behaviour, frequently used to explain food consumption behaviour, posits that in addition to favourable attitudes towards seafood, factors related to perceived behavioural control such as habit, including regular childhood consumption and familiarity with seafood, also influence seafood consumption (Ajzen, 1991; Honkanen, Olsen, \& Verplanken, 2005). 
Seafood consumption is "highly habituated" (Verbeke \& Vackier, 2005, p. 79) with habit being a strong predictor of purchase intention for fish (Juhl \& Poulsen, 2000; Price \& Gislason, 2001; van’t Riet, Sijtsema, Dagevos, \& De Bruijn, 2011). In a Norwegian study, Honkanen, et al. (2005) found that past seafood consumption behaviour and habit, rather than attitudes, explained seafood purchase intentions. Habit should be distinguished from past behaviour, with habit being defined as a behaviour that is automatically repeated without selfinstruction (Honkanen et al., 2005). Habitual behaviours are 'learned sequences of acts that have become automatic responses to specific cues' (Verplanken \& Aarts, 1999, p. 104). These learned sequences of acts are triggered by environmental cues and reinforced with rewarding past experiences (van't Riet et al., 2011; Verplanken \& Aarts, 1999). With habitual behaviours, such as eating, less information is needed to make decisions, consumption intentions are poor predictors of consumption behaviour, and consumption behaviour is stimulated by environmental or situational cues (van’t Riet et al., 2011).

Regular childhood fish consumption, particularly up to age five, has been found to influence fish consumption in later life (Trondsen, Scholderer, Lund, \& Eggen, 2003). Trondsen et al. (2003) found that childhood consumption of at least three fish dinners per week positively influenced adult fish consumption. Conversely, a lack of childhood seafood consumption may lead to lower levels of seafood consumption in adulthood due to food neophobia or a tendency to avoid unfamiliar foods (Fischer \& Frewer, 2009). Indeed, Trondsen et al. (2003) found a relationship between childhood fish consumption and increased perceptions of barriers to consumption including a dislike for the smell of seafood and difficulty preparing seafood. In countries such as Australia and the United Kingdom, seafood consumption in childhood may have primarily involved eating take-away fish and chips, typically on a Friday night, rather than observing seafood being purchased fresh and prepared at home. For others, seafood consumption in childhood may have been reserved for 
special occasions, such as Easter and Christmas, rather than everyday meals. These patterns of childhood consumption may be reflected in seafood consumption in adulthood, and thus create distinct segments based on occasion (e.g. the Friday night fish and chip segment versus the special occasion segment). Limited childhood experience with observing the selection and preparation of seafood may explain lower levels of familiarity with seafood and influence seafood eating habits in adulthood. Conversely, childhood consumption of seafood would lead to more favourable attitudes toward seafood consumption in adulthood.

Familiarity with seafood and experience in buying, storing, preparing and serving seafood have been found to be strong predictors of seafood purchase intentions (Myrland, Trondsen, Johnston \& Lund, 2000). Conversely, a lack of familiarity with preparing fresh seafood means that some consumers perceive difficulty in selecting and cooking seafood (Olsen, 2004; Scholderer \& Grunert, 2001; Sogn-Grundvåg \& Østli, 2009; Sveinsdóttir et al., 2009). Familiarity with a product category influences self-confidence in making decisions with respect to that product category (Verbeke, Vermeir \& Brunso, 2007). People who hold stronger beliefs in their ability to select and prepare fish report higher intentions to purchase fish (Verbeke \& Vackier, 2005). Concern regarding making the right choice when purchasing seafood has been found to be negatively associated with purchase intention; however, concern for making the right choice has been found to have less influence on purchase intention for seafood than either habits or past experiences (Verbeke \& Vackier, 2005).

Based on the literature regarding seafood consumption, we hypothesise that regular seafood consumers are more likely than lighter seafood consumers to:

H1: hold favourable attitudes toward seafood

H2: be familiar with seafood

H3: be in the habit of consuming seafood

H4: have consumed seafood on a regular basis as a child. 
Further, consumers who consumed seafood on a regular basis as a child are more likely to:

H4a: hold more favourable attitudes toward seafood in adulthood

H4b: be familiar with seafood

H4c: be in the habit of consuming seafood.

Finally, we hypothesise that:

H5: patterns of childhood seafood consumption occasions are associated with patterns of adult seafood consumption occasions.

\section{MATERIALS AND METHODS}

In June 2010, a survey of Australian consumers $(n=899)$ was conducted with an online consumer panel of 60,000 active participants. The main purpose of the study was to investigate drivers and barriers to fish consumption in Australia. In this paper, we primarily focus on the findings related to habit including childhood consumption, attitudes toward seafood, familiarity with seafood, and seafood consumption occasions. Survey participants were screened for industry affiliation, participation in seafood research in the past six months, age (18 years and older), whether they were the main or joint grocery shopper in the household, and for having consumed fish in the past three months. Participants were selected as being either regular $(n=296)$, light $(n=303)$ or very light $(n=300)$ fish consumers. Very few Australian consumers are heavy fish eaters (more than 3 times per week). Regular fish consumers purchase and eat fish from 2-3 times per week to at least once a week. Light fish consumers purchase and eat fish about once per fortnight, while very light fish consumers purchase and eat fish once per month.

Females represented 65.9 percent of the sample (Table 1). Seventy-three percent of respondents were the main household shopper. To determine the representativeness of the sample, the respondent profile was compared with Australian census data (Australian Bureau of Statistics, 2011). Respondents in the 55 years and older age bracket (34\%) were the largest 
age group, with respondents under 25 years of age being the smallest age group $(2.7 \%)$. The sample was also highly educated. While age differences were found, no differences based on educational status were evident for any of the items. The respondents covered a representative range of household income categories. In keeping with previous studies, older consumers were more likely to be regular consumers of fish than younger consumers (Olsen, 2003, Trondsen et al., 2003; Verbeke \& Vackier, 2005). No other demographic differences were evident across consumption groups (regular, light and very light).

TABLE 1 Respondent profile $(\mathrm{n}=899)$

\begin{tabular}{llll}
\hline \multirow{4}{*}{ Agender } & & Sample & Population* \\
\hline & Female & 65.9 & 50.6 \\
& Male & 34.1 & 49.4 \\
& 55 years and older & 34.0 & 24.8 \\
& $45-54$ & 29.7 & 13.6 \\
& $35-44$ & 20.1 & 14.2 \\
Education & $25-34$ & 13.5 & 14.3 \\
& $18-24$ & 2.7 & $7.4(20-24 \mathrm{yr})$ \\
Annual household income (AUD) & 47.6 & 23.0 \\
& Tertiary /university & 27.3 & 26.9 \\
& Technical training/TAFE & 25.1 & 50.0 \\
& Secondary/Primary school & 26.7 & 30.3 \\
& 100,000 or above & 26.7 & 23.6 \\
& 60,000 - 99,999 & 27.1 & 34.2 \\
& 20,000 - 59,999 & 24.2 & 11.9 \\
\hline
\end{tabular}

* Source: Australian Bureau of Statistics (2011)

Statements in the survey were drawn from the literature on seafood consumption and recent studies of seafood consumption in Australia and where necessary were adapted to the Australian context for this study (see Table 2 for the statements). To avoid the clustering of responses at the neutral point or positive responses associated with social desirability, and to gain a clearer picture of the relative direction of attitudes, items were measured on either a six-point agreement or a six-point importance scale (Garland, 1991). Attitudes toward seafood were measured on three items (Shepherd \& Raats, 1996). Items for measuring habit were based on previous research by Honkanen et al. (2005) with items drawn from Verplanken and Orbell's (2003) habit strength scale. To capture regular childhood 
consumption we included "I ate fish on a regular basis as a child", and to capture regular consumption in adulthood we added "I serve fish for everyday meals". Familiarity with seafood was measured on three items (Verbeke \& Vackier, 2005). Finally, to investigate the relationship between childhood and adult consumption occasions we included five statements to measure a range of seafood consumption occasions.

Data were analysed using SPSS. Confirmatory factor analysis with principle axis factoring and varimax rotation was conducted on the items measuring attitudes, familiarity, habit and consumption occasions. Cronbach's Alpha tested for item reliability. Descriptive statistics and bivariate correlations were conducted to identify relationships between constructs. Analysis of variance was conducted to identify differences across consumption segments (regular, light and very light fish consumers). Demographic differences were identified through analysis of variance and independent samples t-tests. Levene's test was used to check for homogeneity of variances and post-hoc tests (Tukey HSD) were used to determine the pattern of differences between groups. Differences were deemed significant if the $p$-value was less than 0.05 .

\section{RESULTS}

Confirmatory factor analysis revealed four factors with eigenvalues greater than 1.0 (Table 2). The first factor "Habit" explained 32.3 percent of the variance. The second factor "Consumption Occasion" explained 14.8 percent of the variance. The third factor, explaining a further 8.6 percent of the variance, was "Familiarity", while the fourth factor "Attitude" explained 7.6 percent of variance. The standardised factor loading coefficients and Cronbach's alpha coefficients are presented in table 2.

TABLE 2 Factor Analysis and Reliability Testing

\begin{tabular}{lccc}
\hline Construct/Items & $\begin{array}{l}\text { Variance } \\
\text { Explained }\end{array}$ & $\begin{array}{l}\text { Factor } \\
\text { Loadings }\end{array}$ & $\begin{array}{l}\text { Cronbach } \\
\text { alpha } \\
\text { coefficient }\end{array}$ \\
\hline Habit & $32.3 \%$ & 0.78 \\
\hline
\end{tabular}




\begin{tabular}{|c|c|c|c|}
\hline Fish is regularly included on my shopping list & & 0.79 & \\
\hline Eating fish is something I do without consciously having to & & 0.64 & \\
\hline remember & & -0.58 & \\
\hline Eating fish is something I do NOT do frequently & & 0.56 & \\
\hline I serve fish for everyday meals & & 0.29 & \\
\hline I ate fish on a regular basis as a child & & & \\
\hline Consumption Occasion & $14.8 \%$ & & 0.78 \\
\hline I serve fish for traditional or religious occasions (e.g. Xmas) & & 0.73 & \\
\hline Eating fish on certain occasions was a family tradition when & & & \\
\hline I was a child & & 0.72 & \\
\hline I serve fish on special occasions or for dinner parties & & 0.63 & \\
\hline Our family ate fish on special occasions when I was a child & & 0.58 & \\
\hline I serve fish on a regular occasion each week & & 0.47 & \\
\hline Familiarity & $8.9 \%$ & & 0.85 \\
\hline I am well informed about fish & & 0.77 & \\
\hline I am familiar with preparing fish & & 0.76 & \\
\hline I do NOT know much about how to prepare and serve fish & & -0.73 & \\
\hline Attitude & $7.6 \%$ & & 0.81 \\
\hline Fish usually tastes bad & & 0.87 & \\
\hline Eating fish is usually an unpleasant experience & & 0.73 & \\
\hline I like eating fish & & -0.59 & \\
\hline
\end{tabular}

Linear regression revealed a strong negative association between consumption frequency (regular, light and very light consumption segments) and habit $(\beta=-.24, \mathrm{t}=-7.5, \mathrm{p}$ $=0.00)$ and a moderate association with familiarity with seafood $(\beta=-.09, \mathrm{t}=-2.8,==0.01)$. Correlations between constructs are presented in Table 3. All constructs except consumption occasion were above the mean ( 3.5 on the 6 point scale). Attitudes toward seafood were very positive $($ mean $=5.13)$. The habit measure was also positive $($ mean $=4.21)$, as was familiarity with seafood, although less so $($ mean $=4.06)$. Consumption occasions was just below the mean $($ mean $=3.47)$. We found very few correlations between the constructs; however, habit was correlated weakly correlated with familiarity with seafood $(\mathrm{r}=0.10)$, attitude toward seafood $(r=0.08)$, and consumption occasion $(r=0.07)$.

TABLE 3 Correlations between habit, consumption occasion, familiarity and attitude

\begin{tabular}{lllllrl}
\hline & Habit & $\begin{array}{l}\text { Consumption } \\
\text { Occasion }\end{array}$ & Familiarity & Attitude & Mean & $\begin{array}{l}\text { Vari } \\
\text { ance }\end{array}$ \\
\hline Habit & 1.00 & & & 4.21 & 0.03
\end{tabular}




\begin{tabular}{lllllll} 
Consumption Occasion & $* 0.07$ & 1.00 & & & 3.47 & 0.04 \\
Familiarity & $* * 0.10$ & 0.05 & 1.00 & & 4.06 & 0.03 \\
Attitude & $* 0.08$ & 0.02 & 0.04 & 1.00 & 5.13 & 0.01 \\
\hline
\end{tabular}

** Correlation is significant at the 0.01 level

* Correlation is significant at the 0.05 level

To test our hypotheses, we investigated differences across consumption segments on the basis of attitudes toward seafood, familiarity with seafood, and habit (Table 4).

TABLE 4 Attitude, familiarity, and habit across consumption segments

\begin{tabular}{|c|c|c|c|c|c|c|}
\hline Item & $\begin{array}{l}\text { Total } \\
\text { Mean (SD) }\end{array}$ & $\begin{array}{l}\text { Regular } \\
\text { Mean (SD) }\end{array}$ & $\begin{array}{l}\text { Light } \\
\text { Mean (SD) }\end{array}$ & $\begin{array}{l}\text { Very Light } \\
\text { Mean (SD) }\end{array}$ & $\mathrm{F}$ & Sig \\
\hline $\begin{array}{l}\text { Attitude } \\
\text { I like eating fish }\end{array}$ & $5.2(0.9)$ & $5.4(0.8)^{\mathrm{a}}$ & $5.2(1.0)^{b}$ & $5.1(0.9)^{b}$ & 13.2 & 0.00 \\
\hline Fish usually tastes bad & $1.9(1.0)$ & $1.7(0.9)^{\mathrm{a}}$ & $1.9(1.0)^{\mathrm{b}}$ & $2.0(1.0)^{\mathrm{b}}$ & 5.0 & 0.01 \\
\hline $\begin{array}{l}\text { Eating fish is usually an unpleasant } \\
\text { experience }\end{array}$ & $2.0(1.1)$ & $1.9(1.2)$ & $2.0(1.2)$ & $2.0(1.0)$ & 1.4 & 0.24 \\
\hline $\begin{array}{l}\text { Familiarity } \\
\text { I am familiar with preparing fish }\end{array}$ & $4.1(1.0)$ & $4.4(1.0)^{\mathrm{a}}$ & $4.0(1.0)^{\mathrm{b}}$ & $3.9(1.0)^{b}$ & 20.3 & 0.00 \\
\hline I am well informed about fish & $4.0(1.1)$ & $4.2(1.1)^{\mathrm{a}}$ & $3.9(1.0)^{b}$ & $3.9(1.0)^{b}$ & 9.5 & 0.00 \\
\hline $\begin{array}{l}\text { I do NOT know much about how to } \\
\text { prepare and serve fish }\end{array}$ & $2.9(1.3)$ & $2.7(1.3)^{\mathrm{a}}$ & $3.0(1.2)^{\mathrm{b}}$ & $3.1(1.3)^{\mathrm{b}}$ & 9.6 & 0.00 \\
\hline $\begin{array}{l}\text { Habit } \\
\text { Fish is regularly included on my } \\
\text { shopping list }\end{array}$ & $4.4(1.0)$ & $4.7(1.0)^{\mathrm{a}}$ & $4.4(1.0)^{b}$ & $4.1(1.0)^{\mathrm{c}}$ & 31.9 & 0.00 \\
\hline $\begin{array}{l}\text { Eating fish is something I do } \\
\text { without having to consciously } \\
\text { remember }\end{array}$ & $4.1(1.2)$ & $4.4(1.2)^{\mathrm{a}}$ & $4.0(1.1)^{b}$ & $3.9(1.1)^{b}$ & 14.9 & 0.00 \\
\hline $\begin{array}{l}\text { Eating fish is something I do NOT } \\
\text { do frequently }\end{array}$ & $2.6(1.2)$ & $2.3(1.2)^{\mathrm{a}}$ & $2.7(1.2)^{b}$ & $2.9(1.1)^{\mathrm{c}}$ & 18.5 & 0.00 \\
\hline I serve fish for everyday meals & $4.2(1.1)$ & $4.4(1.1)^{\mathrm{a}}$ & $4.2(1.0)^{\mathrm{a}}$ & $3.9(1.1)^{b}$ & 19.2 & 0.00 \\
\hline $\begin{array}{l}\text { I ate fish on a regular basis as a } \\
\text { child }\end{array}$ & $4.0(1.2)$ & $4.1(1.4)$ & $4.1(1.1)$ & $4.0(1.2)$ & 0.74 & 0.48 \\
\hline
\end{tabular}

The vast majority of respondents in the survey agreed that they like eating fish (97\%).

Regular fish consumers were more likely to agree that they like eating fish than lighter fish 
consumers $(\mathrm{F}(2,896)=13.2, \mathrm{p}=0.00)$. Very few respondents $(5 \%)$ agreed that "fish usually tastes bad", and once again regular fish consumers were less likely to agree with this statement than lighter fish consumers $(\mathrm{F}(2,896)=5.0, \mathrm{p}=0.01)$. Moreover, very few respondents (9\%) agreed that eating fish is usually an unpleasant experience. These findings indicate that Australian consumers hold very positive attitudes toward seafood, with regular seafood consumers holding even more positive attitudes toward seafood than lighter seafood consumers, hence, $\mathrm{H} 1$ is supported.

Three quarters of the respondents (75\%) agreed they were familiar with preparing fish, with regular consumers being more likely to agree than either light or very light consumers $(\mathrm{F}(2,896)=20.3, \mathrm{p}=0.00)$. Over two-thirds $(69 \%)$ of the respondents are well informed about fish, and once again, regular consumers were more likely to agree than either light or very light consumers $(F(2,896)=9.5, p=0.00)$. Over one-third of the respondents (34\%) agreed that they do NOT know much about how to prepare and serve fish, with regular consumers being more likely to disagree with this statement than either light or very light fish consumers $(F(2,896)=9.6, p=0.01)$. Hence, about one-third of Australian consumers indicate a lack of familiarity with fish, with regular consumers being more familiar with fish than lighter consumers, and thus $\mathrm{H} 2$ is supported.

The majority of respondents (84\%) agreed that fish is regularly included on their shopping list. Regular fish consumers were much more likely to agree than either light or very light fish consumers $(F(2,896)=31.9, p=0.00)$. Less than three-quarters of the respondents (71\%) agreed that eating fish is something they do without having to consciously remember, while almost one quarter (23\%) agreed that eating fish is something they do NOT do frequently. Regular fish consumers more strongly agreed that eating fish is something they do without having to consciously remember than lighter fish consumers $(F(2,896)=14.9, p=$ 
0.00). Regular consumers were also more likely to disagree that eating fish is something they do NOT do frequently than either light or very light fish consumers $(F(2,896)=18.5, p=$ 0.00). Just over three-quarters of the respondents (78\%) serve fish for everyday meals. Very light fish consumers were less likely to agree than either light or regular fish consumers $(\mathrm{F}(2,896)=19.2, \mathrm{p}=0.00)$. Hence, about one-quarter of Australian consumers indicate that they are not in the habit of consuming seafood, and this is particularly the case for light and very light fish consumers, thus $\mathrm{H} 3$ is also supported. Just over two-thirds (69\%) of the respondents ate fish on a regular basis as a child, however, no differences across consumption segments were evident on childhood consumption, and hence H4 is not supported.

Despite finding no differences between regular seafood consumption in childhood and adult consumption rates, we did find a moderate positive association between regular childhood consumption and liking to eat fish $(\mathrm{r}=0.28)$, and weak negative associations between regular childhood consumption and the statements "Fish usually tastes bad" $(r=-$ $0.18)$ and "Eating fish is usually an unpleasant experience" $(\mathrm{r}=-0.15)$. Therefore, regular childhood fish consumption appears to have some, albeit weak, influence over attitudes towards seafood in adulthood, and hence, $\mathrm{H} 4 \mathrm{a}$ is supported. Moreover, there was a moderate positive association between regular consumption as a child and being well informed about fish $(r=0.34)$ and being familiar with preparing fish $(r=0.30)$, and a weak negative association with not knowing much about how to prepare and serve fish $\left(r^{2}=-0.27\right)$. Therefore, it appears that regular childhood consumption leads to greater familiarity with seafood in adulthood, and thus H4b is also supported. Finally, we found moderate positive associations between regular childhood consumption and the statements "fish is regularly included on my shopping list" $(\mathrm{r}=0.35)$ and "eating fish is something I do without having to consciously remember" $(\mathrm{r}=0.33)$, and a weak negative association between eating fish on a regular basis as a child with "eating fish is something I do NOT do frequently" $(\mathrm{r}=-0.22)$. 
There were also weak associations between consuming fish on a regular basis as a child and (1) serving fish for everyday meals as an adult $\left(\mathrm{r}^{2}=0.26\right)$ and (2) serving fish on a regular occasion each week as an adult $\left(r^{2}=0.22\right)$. Therefore, regular childhood consumption appears to positively influence adult seafood eating habits and hence, $\mathrm{H} 4 \mathrm{c}$ is also supported.

To investigate whether patterns of childhood seafood consumption occasions would influence seafood consumption occasion patterns in adulthood, respondents were asked about their childhood and adulthood seafood consumption occasions (Table 5).

TABLE 5 Consumption Occasions

\begin{tabular}{|c|c|c|c|c|c|c|}
\hline Item & $\begin{array}{l}\text { Total } \\
\text { Mean (SD) }\end{array}$ & $\begin{array}{l}\text { Regular } \\
\text { Mean (SD) }\end{array}$ & $\begin{array}{l}\text { Light } \\
\text { Mean (SD) }\end{array}$ & $\begin{array}{l}\text { Very Light } \\
\text { Mean (SD) }\end{array}$ & $\mathrm{F}$ & Sig \\
\hline $\begin{array}{l}\text { Our family ate fish on special } \\
\text { occasions when I was a child }\end{array}$ & $3.7(1.2)$ & $3.7(1.3)$ & $3.7(1.1)$ & $3.6(1.1)$ & 1.11 & 0.33 \\
\hline $\begin{array}{l}\text { Eating fish on certain occasions } \\
\text { was a family tradition when I was } \\
\text { a child }\end{array}$ & $3.6(1.3)$ & $3.7(1.4)$ & $3.6(1.3)$ & $3.6(1.3)$ & 0.76 & 0.47 \\
\hline $\begin{array}{l}\text { I serve fish on special occasions } \\
\text { or for dinner parties }\end{array}$ & $3.5(1.3)$ & $3.6(1.3)$ & $3.4(1.3)$ & $3.4(1.3)$ & 2.5 & 0.08 \\
\hline $\begin{array}{l}\text { I serve fish on a regular occasion } \\
\text { each week (e.g. Fridays) }\end{array}$ & $3.5(1.3)$ & $3.9(1.4)^{\mathrm{a}}$ & $3.3(1.2)^{\mathrm{b}}$ & $3.2(1.2)^{\mathrm{b}}$ & 27.2 & 0.00 \\
\hline $\begin{array}{l}\text { I serve fish for traditional or } \\
\text { religious occasions (e.g. Xmas) }\end{array}$ & $3.2(1.5)$ & $3.3(1.5)$ & $3.1(1.5)$ & $3.0(1.4)$ & 2.4 & 0.09 \\
\hline
\end{tabular}

Just over half of the respondents (56\%) agreed that their family ate fish on special occasions when they were a child, and 57 percent agreed that eating fish on certain occasions was a family tradition when they were a child. These relatively low levels of childhood consumption on special occasions may explain why very few adult Australians could be classified as heavy fish consumers. Over half of the respondents $(51.3 \%)$ serve fish on special occasions or for dinner parties, while just less than half of the respondents (48.3\%) serve fish on a regular occasion each week. Regular fish consumers were more likely to agree that they serve fish on a regular occasion each week than lighter fish consumers $(\mathrm{F}(2,896)=27.2, \mathrm{p}=$ 0.00). Less than half of the respondents $(40.6 \%)$ serve fish for traditional or religious 
occasions. There were moderate associations between eating fish as a child on certain occasions as a family tradition and adults who serve fish for traditional or religious occasions $\left(r^{2}=0.49\right)$ and serve fish on special occasions or for dinner parties $\left(r^{2}=0.39\right)$. Likewise, there were moderate associations between eating fish on special occasions as a child and serving fish for traditional or religious occasions as an adult $\left(r^{2}=0.35\right)$ and serving fish on special occasions or for dinner parties as an adult $\left(\mathrm{r}^{2}=0.34\right)$. Therefore, it appears that patterns of childhood consumption occasions influence patterns of adult consumption occasions, and thus H5 is supported.

\section{DISCUSSION AND CONCLUSIONS}

Australian consumers hold very favourable attitudes toward eating seafood, with the vast majority of consumers, and regular seafood consumers in particular, liking to eat fish, not disliking the taste of fish, and finding eating fish to be a pleasant experience. The study also revealed differences across consumption segments on the basis of habit consistent with previous studies (Honkanen et al., 2005; Juhl \& Poulsen, 2000; Price \& Gislason, 2001). Fish consumption is highly habituated and about one-third of Australian consumers do not actively remember to consume seafood and need to be reminded to consume seafood.

Gaining top of mind awareness and getting seafood onto the regular shopping list will help to remind Australian consumers to purchase seafood. The Australian Seafood Industry should act more collaboratively to remind Australian consumers to eat recommended levels of seafood. This could involve following the example of the Australian meat industries with their successful television campaigns. Previous research into fish consumption in Australia indicated that approximately three-quarters of seafood purchases are planned (73\%) rather than impulse purchases (27\%) (Birch et al., 2012). To stimulate impulse purchase of seafood, messages and promotions at the point of sale designed to attract attention and remind people to purchase seafood are required, for example by providing easy step by step recipe cards, in- 
store seafood tastings, cooking demonstrations, or special price promotions to encourage trial. Environmental cues such as creating attractive displays of seafood may trigger consumption by making seafood a more appealing meal option (van't Riet et al., 2011). Moreover, greater availability of fresh seafood in retail outlets and gaining better placement within retail outlets or displaying attractively packaged seafood products in self-serve chiller cabinets may capture the attention of potential impulse buyers (van't Riet et al., 2011).

In keeping with previous studies, familiarity with seafood was found to influence seafood consumption in Australia, with lighter seafood consumers being less informed about fish, less familiar with fish, and not knowing how to prepare and serve fish (Sogn-Grundvåg \& Østli, 2009; Sveinsdóttir et al., 2009; Verbeke et al., 2007). Lack of familiarity with seafood leads some Australian consumers to revert to familiar foods such as meat and poultry, thus reinforcing entrenched eating habits, creating a vicious circle. Consuming more seafood and healthier seafood options relies on Australians, and in particular younger consumers, becoming more familiar and informed about seafood and developing greater knowledge and confidence in selecting and preparing fresh seafood at home.

To stimulate seafood consumption and reduce barriers related to lack of familiarity with seafood, previous studies have frequently recommended information or education-based strategies focusing on the health benefits of seafood or how to select and prepare seafood. However, people with strong habits typically lack interest in information, and thus persuasive communication aimed at changing habits is less likely to reach the intended audience. Indeed, information-based interventions and campaigns, such as healthy eating campaigns, have been found to be less successful in influencing frequently performed behaviours, as is the case with eating habits, than with establishing new health behaviours, such as persuading people to have an annual influenza vaccination (Snyder et al., 2004; van't Riet et al., 2011). Hence, Honkanen et al. (2005, p. 166) argued that intervention strategies for increasing seafood 
consumption should focus on breaking "undesirable habits" and replacing these habits with new behaviour, rather than seeking to influence attitudes through persuasive communications. Changing entrenched eating habits relies on effective behavioural interventions which are grounded in an understanding of habit theory. Such interventions seek to change existing behaviours through encouraging repeated 'new' behaviour in stable contexts with the aim of creating automaticity (van't Riet et al., 2011; Verplanken \& Wood, 2006).

Changing Australians' eating habits will not prove easy as research has revealed evidence of limited meal consideration sets and consumption circles; that is, 10 - 15 meals within the consumers' repertoire that they cook on a regular, cyclical basis (Altintzoglou et al., 2010; Rortveit \& Olsen, 2007). Encouraging consumers to shift from a heavy reliance on meat and poultry based meals to including more seafood based meals in their repertoire will require breaking into that consumption circle. The diffusion of innovations theory proposes that a new product is more likely to be adopted if it is compatible with current ways of meeting a need (Rogers, 1995). Hence, asking Australian consumers to change from favourite recipes may not work; rather consumers should to be encouraged to simply replace the protein component of these recipes with seafood. For example, spaghetti bolognaise is Australia's most popular meal, thus Australians could be encouraged to simply replace the beef mince component with a marinara mix, thus creating spaghetti marinara (ABCDiamond, 2009). Replacing the protein component in other favourite meals such as pizza or stir fries with seafood would be more compatible with current cooking habits than trying to get consumers to tackle a brand new recipe.

The findings reveal that about one-third of Australians did not consume fish on a regular basis as a child, and this may explain lower levels of seafood consumption in Australia as compared to many other nations. In contrast to European studies of seafood consumption (e.g. Trondsen et al., 2003), this study did not uncover differences in 
consumption levels between regular, light and very light consumption segments based on childhood consumption. However, childhood seafood consumption was associated with more favourable attitudes toward seafood, being more familiar with and informed about fish and with greater knowledge in how to cook and prepare fish in adulthood, as well as more positive seafood eating habits. Thus, it is important to encourage childhood fish consumption. In particular, it is important for Australian children to learn how to select and prepare fresh fish at home. This could be achieved through school education programs and by developing tasty and healthy fish products that appeal to children. Providing interesting, fun and engaging information and education on seafood through the use of humorous appeals may make seafood more appealing to children. For example, a television campaign featuring two well-known comedians, focusing on the fact that tasty fish dishes are easy and convenient to prepare, had a positive impact in terms of the main household shopper perceiving an increased demand from their family to serve fish (Scholderer \& Grunert, 2001).

Future research into seafood consumption in western societies, where seafood is not part of the traditional diet, should seek to gain a clearer understanding of the role of eating habits and childhood consumption. In particular, studies could uncover whether childhood seafood consumption is primarily associated with eating cooked fish from take-away stores and eating seafood when dining out, as opposed to children actually learning how to select and prepare healthy seafood meals at home. Moreover, the term 'regular' when used to describe seafood consumption may mean different things to different people, with some people interpreting regular seafood consumption to be weekly and others interpreting regular to be more or less frequently than once per week. Hence, future research may ask more specific questions regarding the frequency of childhood consumption.

In summary, given Australians very positive attitudes toward seafood, strategies seeking to influence attitudes, such as health messages, may not lead to increased seafood 
consumption. Future research needs to focus on investigating strategies and behavioural interventions that acknowledge that seafood consumption is highly habituated, and which will lead to actual changes in consumption behaviour and habits, develop greater familiarity with seafood, and stimulate increased seafood consumption of both Australian adults and children.

Note: This work formed part of a project of the Australian Seafood Cooperative Research Centre, and received funds from the Australian Government's CRCs Programme, the Fisheries R\&D Corporation and other CRC Participants.

\section{REFERENCES}

ABCDiamond (2009). Australia's favourite family meal [WWW page]. URL http://www.abcdiamond.com/australia/australias-favourite-family-meal/

Ajzen, I. (1991). The theory of planned behaviour. Organizational Behaviour and Human Decision Processes, 50(2), 179-211.

Altintzoglou, T., Birch Hansen, K., Valsdottir, T., Øyvind Odland, J., Martinsdóttir, E., Brunsø, K., \& Luten, J. (2010). Translating barriers into potential improvements: the case of new healthy seafood product development. The Journal of Consumer Marketing, 27(3), 224.

Australian Bureau of Statistics (2011). Census data [WWW page]. URL http://www.abs.gov.au/websitedbs/censushome.nsf/home/Data

Birch, D., Lawley, M., \& Hamblin, D. 2012, Drivers and barriers to seafood consumption in Australia, Journal of Consumer Marketing, 29(2), in press.

Bredahl, L., \& Grunert, K. G. (1997). Determinants of the consumption of fish and shellfish in Denmark: An application of the theory of planned behaviour. In J. B. Luten, T. 
Borresen \& J. Oehlenschlager (eds.), Seafood from producer to consumer, integrated approach to quality (pp. 21-30). Amsterdam, Elsevier.

Brunsø, K., Verbeke, W., Olsen, S. O., \& Jeppesen, L. F. (2009). Motives, barriers and quality evaluation in fish consumption situations: exploring and comparing heavy and light users in Spain and Belgium. British Food Journal, 111(7), 699-716.

Danenberg, N., \& Mueller, S. (2011). Omnibus Consumer Research Findings - Wave 2, Australian Seafood Cooperative Research Centre and the UniSA Ehrenberg-Bass Institute for Marketing Science, May 2011.

Fischer, A. R. H., \& Frewer, L. J. (2009). Consumer familiarity with foods and the perception of risks and benefits. Food Quality and Preference, 20(8), 576-85.

Garland, R. (1991). The mid-point on a rating scale: Is it desirable? Marketing Bulletin, 2, 6670.

Honkanen, P., Olsen, S. O., \& Verplanken, B. (2005). Intention to consume seafood--the importance of habit. Appetite, 45(2), 161-8.

Juhl, H. J., \& Poulsen, C. S. (2000). Antecedents and effects of consumer involvement in fish as a product group. Appetite, 34(3), 261-7.

Myrland, Ø., Trondsen, T., Johnston, R. S., \& Lund, E. (2000). Determinants of seafood consumption in Norway: lifestyle, revealed preferences, and barriers to consumption. Food Quality and Preference, 11(3), 169-88.

Olsen, S. O. (2003). Understanding the relationship between age and seafood consumption: the mediating role of attitude, health involvement and convenience. Food Quality and Preference, 14(3), 199-209. 
Olsen, S. O. (2004). Antecedents of Seafood Consumption Behaviour -- An Overview. Journal of Aquatic Food Product Technology, 13(3), 79-91.

Price, D. W., \& Gislason, C. (2001). Identification of habit in Japanese food consumption. Agricultural Economics, 24(3), 289-95.

Rogers, E. M., (1995), Diffusion of Innovations (4 ${ }^{\text {th }}$ ed.). New York, Free Press.

Rortveit, A. W., \& Olsen, S. O. (2007). The role of consideration set size in explaining fish consumption. Appetite, 49(1), 214-22.

Rortveit, A. W., \& Olsen, S. O. (2009). Combining the role of convenience and consideration set size in explaining fish consumption in Norway. Appetite, 52(2), 313-7.

Scholderer, J., \& Grunert, K. G. (2001). Does generic advertising work? A systematic evaluation of the Danish campaign for fresh fish. Aquaculture Economics \& Management, 5(5), 253-71.

Scholderer, J., \& Trondsen, T. (2008). The dynamics of consumer behaviour on habit, discontent and other fish to fry. Appetite, 51, 576-591.

Shepherd, R., \& Raats, M. M., (1996). Attitudes and beliefs in food habits. Handbook of the psychophysiology of human eating. London, UK: John Wiley \& Sons.

Snyder, L. B., Hamilton, M. A., Mitchell, E. W., Kiwanuka-Tondu, J., Fleming-Milici, F., \& Proctor, D. (2004). A meta-analysis of the effect of mediated health communication campaigns on behaviour change in the United States, Journal of Health Communication, 9, 71-96.

Sogn-Grundvåg, G., \& Østli, J. (2009). Consumer evaluation of unbranded and unlabelled food products: The case of bacalhau. European Journal of Marketing, 43(1), 213-28. 
Sveinsdóttir, K., Martinsdóttir, E., Green-Petersen, D., Hyldig, G., Schelvis, R., \& Delahunty, C. (2009). Sensory characteristics of different cod products related to consumer preferences and attitudes. Food Quality and Preference, 20(2), 120-32.

Trondsen, T., Scholderer, J., Lund, E., \& Eggen, A. E. (2003). Perceived barriers to consumption of fish among Norwegian women. Appetite, 41(3), 301-14.

van't Riet, J., Sijtsema, S. J., Dagevos, H., \& De Brujn, G. (2011). The importance of habits in eating behaviour. An overview and recommendations for future research. Appetite, 57(3), 585-96.

Verbeke, W., \& Vackier, I. (2005). Individual determinants of fish consumption: application of the theory of planned behaviour. Appetite, 44(1), 67-82.

Verbeke, W., Vermeir, I., \& Brunsø, K. (2007). Consumer evaluation of fish quality as basis for fish market segmentation. Food Quality and Preference, 18(4), 651-61.

Verplanken, B., \& Aarts, H. (1999). Habit, attitude and planned behaviour. Is habit an empty construct or an interesting case of goal-directed automaticity? In W. Stroebe \& M. Hewstone (Eds.), European Review of Social Psychology, 10, 101-134.

Verplanken, B., \& Orbell, S. (2003). Reflections on Past Behavior: A Self-Report Index of Habit Strength. Journal of Applied Social Psychology, 33(6), 1313-30.

Verplanken, B., \& Wood, W. (2006). Interventions to break and create consumer habits. Journal of Public Policy and Marketing, 25, 90-103. 